\title{
The Effect of SPSS Course to Students Attitudes toward Statistics and Achievement in Statistics
}

\author{
Ratna Jatnika
}

\begin{abstract}
This study is an experimental study conducted to investigate the effect of SPSS (Statistical Package for the Social Sciences) Course to student attitudes and achievement about Statistics for students in Faculty of Psychology Universitas Padjadjaran. Participants in this study were students of the Faculty of Psychology Universitas Padjadjaran who took the course of Statistics 3 (SPSS course). The measurement used was the measurement developed by Schau (2003), named Survey of Attitudes toward Statistics (SATS) that can help understood attitude and how it impacts the learning process. SATS consists of six aspects: Affect (feelings of students toward Statistics), Cognitive competence (attitudes of students about their knowledge and skills when applying Statistics), Value (student attitudes about the usefulness, relevance and benefits of Statistics in personal and professional life), Difficulty (student attitudes about the difficulty of Statistics as a subject), Interest (the interest of students to Statistics), Effort (student efforts to learn Statistics). The data analysis will be calculated using the Wilcoxon test and $t$ test. The results of the data processing show that here is a significant increase in the cognitive aspects of learning Statistics after using SPSS but there is a significant decrease in achievement.
\end{abstract}

Index Terms-SPSS, student attitudes, achievement in statistics.

\section{INTRODUCTION}

Student in Faculty of Psychology think that Statistics is very difficult for them, because Statistics is viewed as a hard science than Psychology which is viewed as a soft science. Many of us who teach statistics have to work hard in improving our instruction.

Part of that effort needs to be directed toward developing and using good assessments. Theory, research, and the experiences of both teachers and students of statistics indicate that attitudes toward statistics are important in the teaching-learning process.

"Attitude" plays an important role in social psychology. [1] revealed a global definition of attitude, namely; "Attitude is a disposition of an individual to respond positively or negatively to ... various ... aspects that can be separated from the world of individuals". In this case, the "world" as the associated statistics. The teachers and students of statistics believe that attitudes toward statistics are important. Students who feel and express negative attitudes can create an uncomfortable atmosphere of the class [2]. Attitude affects achievement and the use of statistics in the life outside the classroom.

Manuscript received May 4, 2014; revised July 19, 2014.

Ratna Jatnika is with the Faculty of Psychology Universitas Padjadjaran Bandung, Indonesia (e-mail: ratnajatnika@yahoo.com).
Attitudes are multi-dimensional. Attitude consists of the constructs or factors that -although related- but different from each other. Three factors expectancy-value is most often used in statistical learning include: 1) hope to succeed (Expectation to Success): Student self-concept of their ability to understand statistics. 2) difficulty of the task (Task Difficulty): student perceptions of difficult or not difficult statistics. 3) The value of the task (Task Value): students' perceptions about the value of using statistics. Each of these factors is an important component of attitudes toward statistics.

The Survey of Attitudes toward Statistics (SATS) is developed by [2] help us to understand these attitudes and how they impact in teaching and learning.

SATS consists of six aspects:

- affect (student's feeling concerning statistics)

- cognitive competence (student's attitudes about their intellectual knowledge and skill when applied statistics)

- value (student's attitudes about their usefulness, relevance, and worth of statistics in personal and professional life)

- difficulty (student's attitudes about the difficulty of statistics as a subject)

- interest (student's level of individual interest in statistics) and

- effort (amount of work the student expends to learn statistics)

Reference [3] shows that a study which has conducted to adapt SATS at 81 students in Faculty of Psychology Universitas Padjadjaran shows that SATS has Goodness of Fit Index $=0.89$, Root Mean Square Error of Approximation $($ RMSEA $)=0.017$ and Chi-Square $=9.26(P=0.32)$. Cronbach Alpha coefficient for SATS:

1) Affect (0.844)

2) Cognitive (0.766)

3) Value (0.716)

4) Difficulty (0.400)

5) Interest (0.828)

6) Effort (0.783)

From those result, we can conclude that SATS is a good measurement for measure student's attitude toward Statistics.

Various attempts have been made to improve student attitudes toward statistics, so that students have more positive attitudes. One of the efforts is to transform the curriculum of Statistics in Faculty of Psychology Universitas Padjadjaran by adding SPSS courses since 2009. SPSS (Statistical Package for the Social Sciences) is a software package used for statistical analysis. Long produced by SPSS Inc., it was acquired by IBM in 2009. The current versions (2014) are officially named IBM SPSS Statistics. Companion products in the same family are used for survey authoring and deployment (IBM SPSS Data Collection), data mining (IBM 
SPSS Modeler), text analytics, and collaboration and deployment (batch and automated scoring services).

The software name stands for Statistical Package for the Social Sciences (SPSS), reflecting the original market, although the software is now popular in other fields as well, including the health sciences and marketing [4].

SPSS is a widely used program for statistical analysis in social science. It is also used by market researchers, health researchers, survey companies, government, education researchers, marketing organizations, data miners, and others [5]. The original SPSS manual has been described as one of "sociology's most influential books" for allowing ordinary researchers to do their own statistical analysis. In addition to statistical analysis, data management (case selection, file reshaping, creating derived data) and data documentation (a metadata dictionary is stored in the data file) are features of the base software [6].

The addition of SPSS course in Faculty of Psychology Universitas Padjadjaran is done in the hope that students can more easily calculate various statistics analysis so that Statistics will be perceived as an easy course. In other words, the addition of this course will be expected to improve student attitudes toward statistics and achievement in statistics.

SPSS course conducted using SPSS practicum in the computer lab. Students are given statistics modules calculated manually which has been studied in a previous semester in Statistics 1 and Statistics 2 and also calculated using SPSS software. At each learning module described the steps that must be done when using SPSS software.

SPSS course consists of 2 credits with 14 times lectures and each lecture consists of 200 minutes. At each lecture the student will try to calculate various statistical data analysis using SPSS software. SPSS course started with a material database and data handling in SPSS, followed by material descriptive statistics, parametric statistics consisting of $t$ test and analysis of variance, non-parametric statistics and correlation and regression analysis.

Lectures in the form of practicum in a computer lab, has never been delivered in the Faculty of Psychology, Universitas Padjadjaran. So this course is the only lectures using the computer lab.

The addition of this course has not been evaluated. Therefore, in this study we want to know how the effect of SPSS course to students attitudes toward Statistics and achievement in Statistics. Specifically the research question in this research is "Is there a significant difference of student attitudes toward Statistics and achievement in Statistics before SPSS course and after SPSS course?"

\section{METHODS}

\section{A. Variables}

\section{1) SATS}

- affect (student's feeling concerning statistics)

- cognitive competence (student's attitudes about their intellectual knowledge and skill when applied statistics)

- value (student's attitudes about their usefulness, relevance, and worth of statistics in personal and professional life)
- difficulty (student's attitudes about the difficulty of statistics as a subject)

- interest (student's level of individual interest in statistics) and

- effort (amount of work the student expends to learn statistics)

\section{2) Achievement in statistics}

Achievement in Statistics is a combination score of the midterms, final exams, assignments and quizzes

Measuring instruments used to measure SATS is a measurement tool developed by [2], named Survey of Attitudes toward Statistics (SATS) that can help to understand attitude and how it impacts to the teaching and learning process. The SATS has two major uses. The first use is to help instructors evaluate their students' attitudes toward statistics at the beginning and at the end of their statistics courses. The second is for educational research into students' statistics attitudes.

The original version of the SATS (called the SATS-28) contains 28 items that use a Likert-type scale to assess four components of students' attitudes toward statistics. The current version of the SATS (the SATS-36) contains 36 items that assess six components: the four components from the SATS-28 and two new components.

\section{B. Sampling}

Respondents in this study were students of the Faculty of Psychology, Universitas Padjadjaran who took the course of Statistics 3 (SPSS course). The sampling technique is done by using the total sampling where all students participating in course of Statistics 3 will be taken as a participant.

\section{Data Collection Methods}

The data was collected using a questionnaire SATS (Survey of Attitudes toward Statistics) which was developed by [2], and achievement of Statistics. The questionnaire consists of 36 items with the following composition:

1) Affect consists of 6 items

2) Cognitive competence consists of 6 items

3) Value consists of 9 items

4) Difficulty consists of 7 items

5) Interest consists of 4 items

6) Effort consists of 4 items

\section{Statistical Analysis Technique}

Data obtained from this study will be data with ordinal scale measurement (student attitudes toward Statistics) and interval scale measurement (achievement in Statistics). Therefore to answer the formulation of research problems, the data will be processed using the Wilcoxon test and test. Data processing will be performed using SPSS 18 for Windows.

\section{E. Data Collection Time}

This study is a field quasi-experimental using the one-group pretest posttest design, which is done to determine the effect on SPSS course to student attitudes toward Statistics and achievement in Statistics. In this research, data collection will be conducted at two time points:

1) at the beginning of the semester

2) at the end of the semester 
This research design can be described as follow:

O1 ---------- X ---------- O2

O1: Student attitudes toward Statistics and achievement in Statistics before SPSS course

$\mathrm{X}$ : SPSS course

O2: Student attitudes toward Statistics and achievement in Statistics after SPSS course

\section{RESULT AND DISCUSSION}

\section{A. Result}

TABLE I: MEDIAN OF SATS ASPECTS BEFORE AND AFTER SPSS COURSE

\begin{tabular}{|c|c|c|}
\hline ASPECTS & $\begin{array}{c}\text { MEDIAN } \\
\text { BEFORE SPSS } \\
\text { COURSE }\end{array}$ & $\begin{array}{l}\text { MEDIAN AFTER } \\
\text { SPSS COURSE }\end{array}$ \\
\hline AFFECT & 25 & 25.5 \\
\hline COGNITIVE & 27 & 29 \\
\hline VALUE & 43.5 & 41 \\
\hline DIFFICULTY & 22 & 23 \\
\hline INTEREST & 18 & 18 \\
\hline EFFORT & 23 & 24 \\
\hline
\end{tabular}

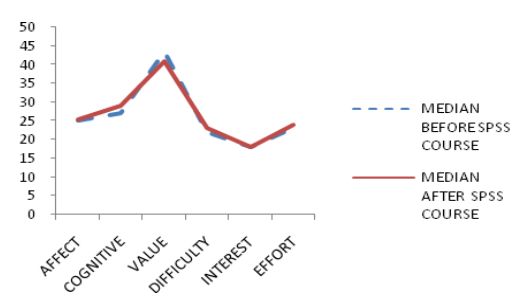

Fig. 1. Median of SATS aspects before and after SPSS course.

Students participating in Statistics courses are 93 people. On this research data collected is 67 students because there are some students who are not present at the time of data collection. The results of measurements SATS can be seen in Table I and Fig. 1 above:

The result of Wilcoxon Test to see the difference of SATS aspects before and after SPSS course can be seen in Table II:

TABLE II: WILCOXON TEST OF SATS ASPECTS BEFORE AND AFTER SPSS

\begin{tabular}{cccc}
\multicolumn{4}{c}{ COURSE } \\
\hline \hline ASPECTS & $\mathrm{Z}$ & $\mathrm{p}$ & \\
\hline AFFECT & -1.033 & 0.301 & - \\
COGNITIVE & -2.293 & 0.022 & $* *$ \\
VALUE & -0.512 & 0.608 & - \\
DIFFICULTY & -0.659 & 0.510 & - \\
INTEREST & -0.554 & 0.579 & - \\
EFFORT & -0.782 & 0.434 & - \\
\hline \hline$* * p<0.05$ & & &
\end{tabular}

Based on calculations that have been presented in the previous section, it appears there is only one aspect that increased significantly after the implementation of SPSS course. The aspect is cognitive aspects $(p=0.022)$.

TABLE III: MEAN OF ACHIEVEMENT IN STATISTICS BEFORE AND AFTER SPSS COURSE

\begin{tabular}{|c|c|c|c|}
\hline \multirow[t]{2}{*}{ ASPECTS } & BEF & $\begin{array}{l}\text { ORE SPSS } \\
\text { OURSE }\end{array}$ & $\begin{array}{l}\text { AFTER SPSS } \\
\text { COURSE }\end{array}$ \\
\hline & MEAN & $\begin{array}{l}\text { STANDARD } \\
\text { DEVIATION }\end{array}$ & MEAN $\begin{array}{l}\text { STANDARD } \\
\text { DEVIATION }\end{array}$ \\
\hline ACHIEVEMENT & 91.57 & 4.76 & 62.58 \\
\hline
\end{tabular}

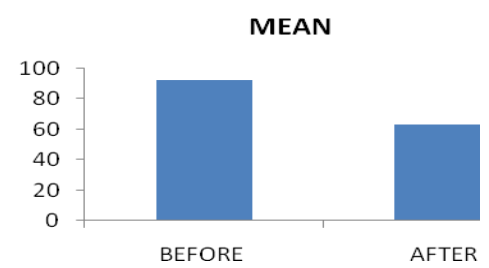

Fig. 2. Mean of achievement in statistics before and after SPSS course

Based on calculations that have been presented in the previous section, it appears that Achievement in Statistics decreased significantly after the implementation of SPSS course $(p=0.000)$.

\section{B. Discussion}

The ultimate goal of statistical learning not only produces students who get a good test score on this course. But more importantly is to produce students who can use statistical patterns of thinking appropriately. Operationally, this statistical mindset can be achieved if students have a positive attitude towards statistics. Therefore, teachers need to design statistical learning process not only makes the students get good test scores, but also has a positive attitude towards statistics.

One of the methods of statistical learning is expected to enhance the students attitude in Faculty of Psychology becomes more positive is the practicum learning methods. This is because through practicum learning methods, students live and learn to practice the subject matter of statistics in the context of psychological research appropriate and get immediate feedback when making a mistake.

Changes in student attitudes to statistics course became more positive are expected to occur in the sixth aspect of attitudes toward statistics, namely affect (student's feeling concerning statistics), cognitive competence (student's attitudes about their intellectual knowledge and skill when applied statistics), value (student's attitudes about their usefulness, relevance, and worth of statistics in personal and professional life), difficulty (student's attitudes about the difficulty of statistics as a subject), interest (student's level of individual interest in statistics) and effort (amount of work the student expends to learn statistics).

After obtaining SPSS, student attitudes regarding the knowledge and skills when applying statistics increased significantly, but student achievement in Statistics decreased significantly. This means that after following SPSS course, the students felt that their knowledge and skills in using statistical science increased, although achievement is decreased. This is thought to occur because students feel anxious when using the computer. Various possibilities of computer misuse are thought to cause anxious students during exam using a computer.

TABLE IV: T TEST OF ACHIEVEMENT IN STATISTICS BEFORE AND AFTER SPSS COURSE

\begin{tabular}{cccc}
\hline \hline ASPECTS & $\mathrm{T}$ & $\mathrm{P}$ & \\
\hline ACHIEVEMENT & -14.650 & 0.000 & $* *$ \\
$* *: p<0.05$ & & & \\
\hline \hline
\end{tabular}

There are some aspects of that attitude also increased, but not significantly, the student feelings concerning statistics, student attitudes about the difficulty of statistics and amount of work the student expends to learn statistics. 
While student interest in the statistic are not increased significantly before and after SPSS course, so this method has not been able to increase student interest of psychology student in statistics course.

There is one aspect that is decreased after SPSS course, namely the attitude of students regarding attitudes about their usefulness, relevance, and worth of statistics in personal and professional life.

With the above results, it can be said that the SPSS course that have been done have not been able to improve student attitudes toward statistics courses become more positive. Because attitudes influence achievement and the use of statistics in life outside the classroom, it can be said that SPSS course that has been done is increased knowledge and skills in the use of statistical sciences, but have not been able to achieve the ultimate goal using statistical patterns of thinking precisely in statistics outside of class.

After measure student attitudes toward statistics, the lecturer can make efforts aimed to influence the student attitude towards statistics. Efforts to do are as follows:

1) Encourage students who possess negative attitudes toward statistics to follow the counseling process

2) Bring a positive attitude in lectures statistics

3) If faculty believe that student attitudes toward statistics is an important thing, relayed this to the student

4) Use of activities that will help students to know and be aware of their attitudes toward statistics

5) Provide a good method of teaching in the lecture

6) Tell the students that mistakes can be made by students and also by the teacher, and the error can be used as media for learning

Indeed, there are few studies that measure the effectiveness of those approaches. Those points of view above derived from the theory of educational psychology and cognitive psychology. Whichever approach is used, the approach should feel comfortable both by teacher and by students.

\section{REFERENCES}

[1] I. Ajzen, Attitude Structure and Behavior, Hillsdale, NJ: Lawrence Erlbaum, 1989, pp. 241-274.

[2] C. Schau, "Students' attitudes: The "other" important outcome in statistics education," presented at 2003 Joint Statistical Meetings Section on Statistical Education, 2003.

[3] R. Jatnika, "The psychometric properties of student attitudes toward statistics," presented at International Meeting of Psychometric Society, Hongkong, 2011.

[4] D. Quintero, T. Ancel et al., (2012). Workload Optimized Systems: Tuning POWER7 for Analytics. [Online]. Available: http://www.redbooks.ibm.com/abstracts/sg248057.html?Open

[5] KDnuggets. (May 2013). KDnuggets Annual Software Poll: Analytics/Data mining software used? [Online]. Available: http://www.kdnuggets.com/polls/2013/analytics-big-data-mining-data -science-software.html

[6] B. Wellman, "Doing it ourselves: The spss manual as sociology's most influential recent book," Required Reading: Sociology's Most Influential Books, D. Clawson Ed., University of Massachusetts Press, 1998, pp. 71-78.

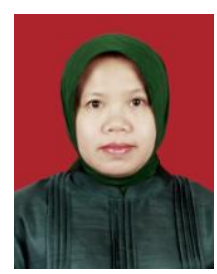

Ratna Jatnika was born in Bandung Indonesia on December 2, 1963. She graduated from the Department of Statistics Faculty of Mathematics and Natural Sciences Universitas Padjadjaran in 1987. She finished the doctoral program in the Department of Industrial Management Institute of Technology Bandung in 2006.

She works as a lecturer at the Faculty of Psychology Universitas Padjadjaran Bandung Indonesia since 1988 for subjects Statistics, Psychometric, Test Contractions, and Experimental Psychology. She is currently conducting research to develop a variety of instructional methods for teaching statistics and is also developing software for teaching statistics at the Faculty of Psychology Universitas Padjadjaran.

Dr. Ratna Jatnika is a member of APA (American Psychological Association), IAAP (International Association of Applied Psychology) and ESRA (European Survey Research Association). She became a best lecturer in Universitas Padjadjaran in 2007. She was honored as the best rendering research grant competition organized by the Ministry of Education in Indonesia. 